\title{
ChemComm
}

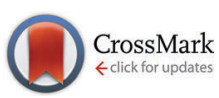

Cite this: Chem. Commun., 2016, 52, 12913

DOI: $10.1039 /$ c6cc90470j

www.rsc.org/chemcomm

\section{Correction: Fluorescent vesicles formed by simple surfactants induced by oppositely-charged carbon quantum dots}

\author{
Xiaofeng Sun, ${ }^{\text {ab }}$ Qinghong Zhang, ${ }^{a}$ Keyang Yin, ${ }^{a}$ Shengju Zhou ${ }^{\text {ab }}$ and \\ Hongguang Li*a
}

Correction for 'Fluorescent vesicles formed by simple surfactants induced by oppositely-charged carbon quantum dots' by Xiaofeng Sun et al., Chem. Commun., 2016, 52, 12024-12027.

The authors wish to clarify statements made in the original article regarding the cryo-TEM image shown in Fig. 2d. In the original article, the authors stated that the cryo-TEM image showed vesicles, however, this conclusion cannot be supported by the data provided, and Fig. $2 \mathrm{~d}$ of the original article likely only shows ice contamination. Whilst Fig. $2 \mathrm{~d}$ and the interpretation of the cryo-TEM image is ambiguous, this has no impact on the overall conclusions of the paper.

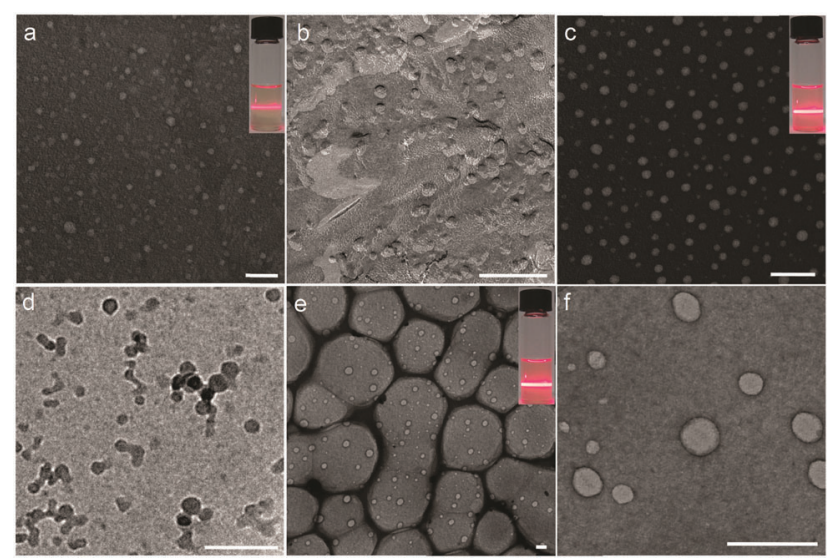

Fig. 2 Typical NS-TEM (a, c, e and f), FF-TEM (b) and cryo-TEM (d) images of the turbid samples containing $1.0 \mathrm{mmol} \mathrm{L}^{-1} \mathrm{SO}$ (a and b), $1.2 \mathrm{mmol} \mathrm{L}^{-1}$ SDS ( $c$ and d) and $0.6 \mathrm{mmol} \mathrm{L}^{-1}$ AOT (e and f). Inset photographs in $a, c$ and e are indicative of the Tyndall effect. The concentration of CQDs is fixed at $0.5 \mathrm{mg} \mathrm{mL}^{-1}$. The scale bar corresponds to $200 \mathrm{~nm}$.

The Royal Society of Chemistry apologises for these errors and any consequent inconvenience to authors and readers.

\footnotetext{
${ }^{a}$ State Key Laboratory of Solid Lubrication \& Laboratory of Clean Energy Chemistry and Materials, Lanzhou Institute of Chemical Physics, Chinese Academy of Sciences, Lanzhou, Gansu Province, 730000, China. E-mail: hgli@licp.cas.cn

${ }^{b}$ University of Chinese Academy of Sciences, Beijing, 100049, China
} 